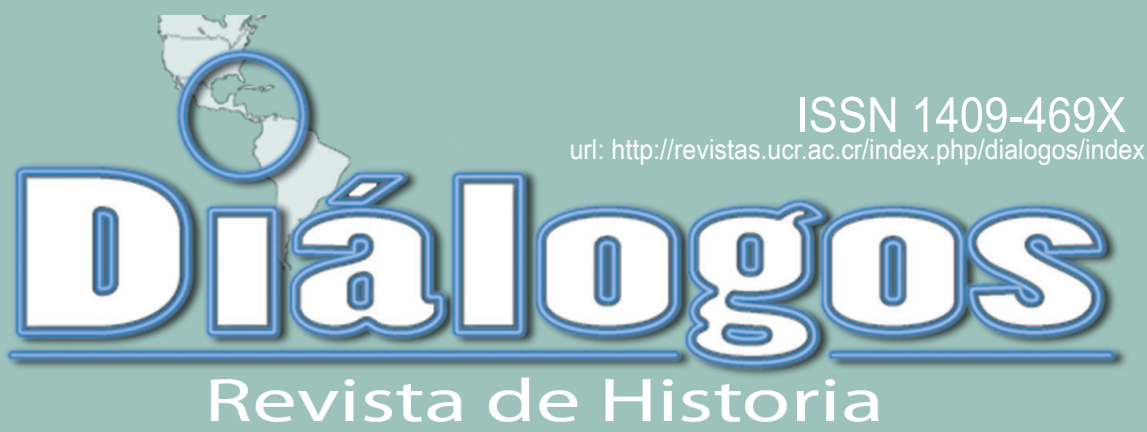

Escuela de Historia. Universidad de Costa Rica Vol. 15 No. 2 Setiembre 2014 - Enero 2015

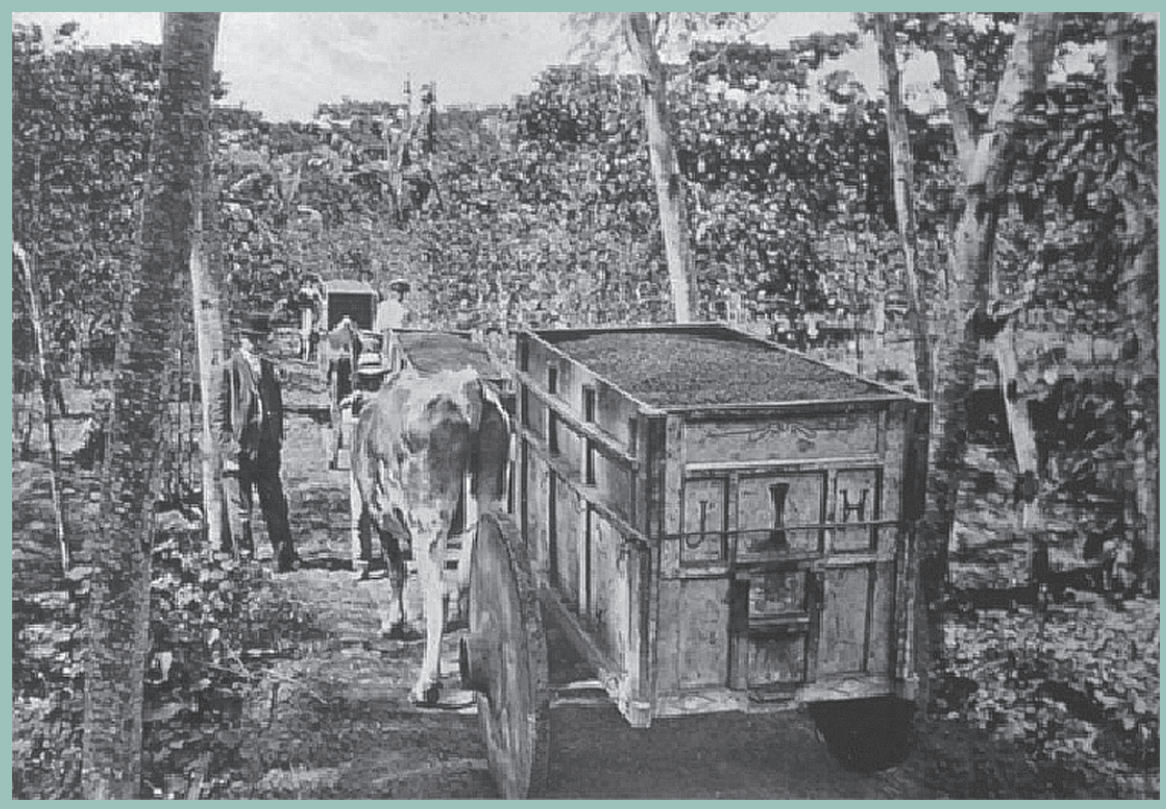

Director de la Revista: Dr. Juan José Marín Hernández juan.marinhernandez@ucr.ac.cr

Editor académico: Dr. David Díaz Arias - david.diaz@ucr.ac.cr Editor técnico: M.Sc. Marcela Quirós G. - marcela.quiros@ucr.ac.cr

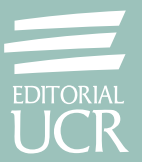




\title{
LA CARA DE LA PATRIA EN PAPEL Y METAL: LA ESCULTURA EN LA FILATERÍA Y NUMISMÁTICA
}

\section{THE FACE OF THE COUNTRY ON PAPER AND METAL: SCULPTURE IN FILATERÍA AND NUMISMATICS}

Leoncio Jiménez Morales

\section{Palabras claves}

Historia nacional, identificación nacional, numismática, monumentos, iconografía.

\section{Keywords}

National history, national identification, numismatics, sights, iconography.

Fecha de recepción: 1 de diciembre, 2013 - Fecha de aceptación: 12 de junio 2014

\section{Resumen}

El presente artículo estudia la visión y percepciones trasmitidas sobre las esculturas monumentales existentes en Costa Rica, que se representan en las estampillas postales, monedas y billetes emitidos en el país. De esta manera se analizan los posibles mensajes que el Estado costarricense difundía y promocionaba al vincular con la escultura monumental, que constituye un instrumento de propaganda estatal por sí misma, con otros medios de impacto masivo contralados por el Gobierno.

\begin{abstract}
This article explores the vision and perceptions transmitted on existing monumental sculptures in Costa Rica, which is represented on postage stamps, coins and banknotes made in the same Republic. This will analyze the possible messages that the Costa Rican government spread and promoted, by linking to monumental sculpture of state propaganda instrument itself, with other means of massive impact control for him.
\end{abstract}


En el proceso de construcción del Estado Nacional, el gobierno de dicha Nación busca transmitir mensajes que le permitan influir en la población base de su nación. De esta forma, existen maneras privilegiadas que utilizan los gobiernos para comunicar a las masas sus ideales y propuestas de vida. Uno de estos medios son los monumentos escultóricos cívicos, los cuales son creados para exaltar a los grandes ciudadanos, las gestas patrióticas y los valores cívicos que el Estado considera indispensables para la consolidación de la ciudadanía y formación de la identidad nacional. Debido a que los monumentos están evidentemente limitados por su incapacidad de movilidad, el mensaje puede ser potencializado por otros medios, que lleguen masivamente a la población de otros emplazamientos de la República. Muchos de esos medios a disposición del Estado no son creados propiamente con del propósito de ser canales de comunicación ideológica, sino más bien con fines utilitarios, tal es el caso de las estampillas y las monedas. Sin embargo, estas conjuntamente llegan a toda la población del país y se proyectan a nivel internacional.

Las estampillas postales al estar ligadas al correo, uno de los medios de comunicación más utilizados, son en sí mismas un instrumento para la transmisión de ideales nacionales y sus emblemas. Así mismo, las monedas y billetes no son solo una herramienta para el intercambio comercial, sino que se han manifestado como una forma de expresión de mensajes sobre los emisores y dan gran información sobre la sociedad de la época, sobre todo de los gobernantes y los símbolos de prosperidad y poder. Las imágenes que muestran las estampillas, monedas y billetes no son casuales; y en este caso, que nos interesa en particular, la presencia de monumentos escultóricos refuerza los ideales de la identidad nacional y de sus principales manifestaciones plásticas-culturales. En esta investigación se estudian dichas representaciones en cada entorno comunicativo.

\section{"VISTAS POR TODO EL MUNDO" LA ESCULTURA PÚBLICA MONUMENTAL EN LA FILATELIA}

Más allá de su uso utilitario, las estampillas o timbres postales, poseen un valor simbólico y comunicativo muy influyente en las poblaciones. Lo anterior es particularmente cierto antes de 1950 cuando el bajo costo del correo frente al telégrafo y la dificultad de acceso al teléfono, lo hacían el medio preferente para las comunicaciones a distancia, haciendo de la estampilla objeto obligado y por lo tanto, visto y manejado por un público amplio. Posterior a esa fecha, la popularización del teléfono y de las formas digitales de comunicación han hecho que el correo físico sea desplazado y utilizado muy puntualmente, sin embargo, las 
estampillas comienzan a cotizarse como elementos coleccionables, aumentando su poder simbólico como comunicadoras de ideales.

Tras su aparición en 1840, en Inglaterra, la estampilla o sello postal se constituyó en un mecanismo para garantizar el pago apropiado de los envíos mediante un sistema moderno de correo, cuyo uso se difundió con gran rapidez por el planeta. Ya desde este momento, el sello postal presentaba similitudes con la numismática, no solo en el hecho de que ambos eran productos fiduciarios (el sello confirma un pago previo y la moneda es medio de pago), sino en su utilización para trasmitir ideas y en este caso particular, a partir de su diseño. El Penny Black, utilizó la imagen que se mostraba en las monedas inglesas en un momento de expansión comercial: la efigie de la Reina Victoria, de perfil izquierdo. (Hidalgo, 2009, p. 15).

En Costa Rica, al ser producidas y reguladas por el Estado desde 1863 (Dirección de Correo y telégrafos, 2011), las estampillas muestran imágenes que el Estado, no solo considera "representativas" de la nación costarricense, sino que además, apoyan sus discursos e intereses temporales a corto o mediano plazo. De esta forma, los personajes ilustres, paisajes geográficos relevantes, expresiones culturales u "objetos representativos" del país son utilizados en los timbres, en un elemento que, a la vez, se muestra como producto cultural y expresión del discurso oficial (Hidalgo, 2009, p. 113). La propaganda a las esculturas monumentales no solo pone en evidencia, sino que también alardea del poder económico, técnico y plástico para desarrollar la obra como tal, sino al ideal que se le rinde pleitesía y unifica el sentimiento cívico o estético del país.

De esta forma, las estampillas postales que muestran esculturas monumentales cumplen una doble función ideológica para el Estado. En primer lugar, difunden en amplias masas de la población nacional, y en el público internacional que puede llegar a contactar, una iconografía sobre el arte y sobre obras cúlmenes de la estética nacional. En segundo lugar, propaga ideales y valores (correlacionados al motivo de la obra escultórica) como valores del Estado Nacional. Por tal razón, el análisis de estas estampillas da razón de los intereses estatales en cuando a su agenda política-cultural.

Desde la aparición de la primera estampilla nacional hasta la fecha, se registran 21 de ellas con diferentes diseños que muestran una escultura monumental ubicada en el territorio costarricense. Como muestra la Figura 1, la representación más frecuente es la del Monumento Nacional, con 11 estampillas, le sigue muy por detrás el Monumento a Juan Santamaría, con 5, el Monumento al Agricultor, con 2; así como el Monumento a la Madre, la Estatua de Juan Mora Fernández y la Estatua de Juan Mora Porras, con un ejemplar cada uno. 


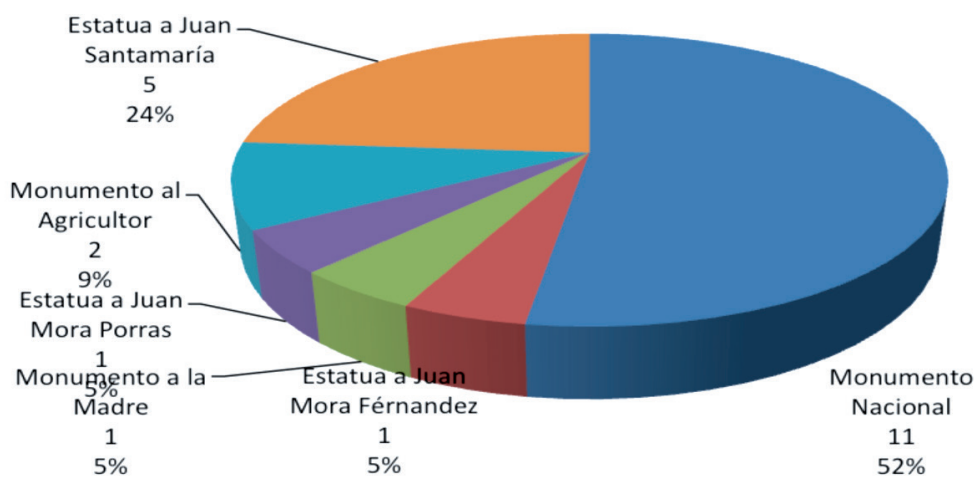

Figura 1. Esculturas públicas representadas en estampillas costarricenses. Fuente: Standard postage Stamp Catalogue Scoot, 2010. Elaboración propia.

Del total de los 21 diseños, 17 de ellos conmemoran la Campaña Nacional de 1856-1857, o a uno de sus protagonistas, lo que refiere la importancia simbólica que se asigna a este acontecimiento histórico como elemento identitario del costarricense. Así mismo, del total de diseños, solo las estampillas en que se representan el Monumento a la Madre y el Monumento a Juan Santamaría, de 1981 y el Monumento Nacional, de 1989, utilizan la fotografía para reproducir la imagen; en el resto se confeccionan con fotograbados, lo que implica una distorsión artística de la estructura de la obra, en función del interés expresivo del artista, como se puede ver en la Tabla 1.

En cuanto a los años de edición, en 1901, 1907, 1910, 1923 a 1926 y 1931 se imprimió solo una estampilla por año, con diversos diseños entre sí. El timbre producido en el año de 1923 se dedicó al Monumento Nacional (visualizándose todo el conjunto monumental desde su costado sur), el de 1931 al Monumento Juan Mora Porras (solo la escultura de forma frontal); mientras que las otras cuatro representaban la escultura a Juan Santamaría (mostrándose en las dos primeras desde la base y la última solo la escultura, todas de tres cuartos del perfil sur). En 1955 y 1974 se emitieron 3 y 4 estampillas respectivamente, en cuyo diseño figuraba el Monumento Nacional, las que se distinguen entre sí por la combinación cromática. A partir de un diseño principal existente en cada edición, todas representaban el Monumento completo desde su costado sur. En 1979 se emitió una estampilla que mostraba el Monumento a la Madre, desde un contrapicado de su figura central. La estampilla producida en 1981 representaba solamente la escultura del Monumento a Juan Santamaría y en ella se utilizó por primera vez una fotografía para ilustrar la obra, la cual se presentaba desde el costado sur. En 1984 se emitieron dos diseños de estampillas que mostraban únicamente las esculturas (sin la base ni el pedestal) del Monumento a Juan Mora Fernández y el Monumento Nacional, de frente la primera y de tres cuarto de frente desde el costado sur, la segunda; con motivo de la X Exposición Filatélica Nacional realizada del 10 al 16 de setiembre de ese año. 


\section{Tabla 1}

ESTAMPILLAS COSTARRICENSE QUE REPRESENTAN ESCULTURAS PÚBLICAS

\begin{tabular}{|c|c|c|c|c|}
\hline $\begin{array}{c}\text { VALOR } \\
\text { FRACCIONAL }\end{array}$ & COLORES & AÑO & OBRA & $\begin{array}{l}\text { RE O SOBRE } \\
\text { IMPRESIÓN }\end{array}$ \\
\hline$\varnothing 0,01$ & Verde y negro & 1901 & Estatua a Juan Santamaría & 1(1911) \\
\hline$\phi 0,01$ & Rojas café e índigo & 1907 & Estatua a Juan Santamaría & $2(1908,1921)$ \\
\hline$\notin 0,01$ & Café & 1910 & Estatua a Juan Santamaría & 0 \\
\hline$\phi 0,01$ & Violeta & $1923-1926$ & Monumento Nacional & 0 \\
\hline$\notin 0,13$ & Rosa carmesí & 1931 & Estatua a Juan Rafael Mora & $1(1941)$ \\
\hline$\varnothing 0,05$ en $\varnothing 0,02$ & Esmeralda sobre marca en rojo & 1955 & Monumento Nacional & 0 \\
\hline$\varnothing 0,15$ en $\varnothing 0,02$ & Esmeralda & 1955 & Monumento Nacional & 0 \\
\hline$\varnothing 0,15$ en $\varnothing 0,02$ & Esmeralda & 1955 & Monumento Nacional & 0 \\
\hline$\notin 0,50$ & Café sobre impreso en negro & 1974 & Monumento Nacional & 0 \\
\hline$\phi 1$ & Violeta sobre impreso en negro & 1974 & Monumento Nacional & 0 \\
\hline$\not 2$ & Naranja sobre impreso en negro & 1974 & Monumento Nacional & 0 \\
\hline$\phi 5$ & Oliva sobre impreso en negro & 1974 & Monumento Nacional & 0 \\
\hline$\not 20$ & Multicolor & 1979 & Maternidad & \\
\hline$\phi 1$ & Multicolor & 1981 & Estatua a Juan Santamaría & 0 \\
\hline$\not 10$ & Rojo y dorado & 1984 & Juan Mora Fernández & \\
\hline$\not 10$ & Azul y dorado & 1984 & Monumento Nacional & \\
\hline$\not 6$ & Negro y púrpura & 1985 & Monumento al Agricultor & 0 \\
\hline$\not 1$ & Multicolor & 1985 & Monumento al agricultor & \\
\hline$\not 30$ & Multicolor & 1989 & Monumento Nacional & \\
\hline$\not 85$ & Café y ocre & 2006 & Monumento Nacional & 0 \\
\hline$\varnothing 85$ & Café y ocre & 2006 & Estatua a Juan Santamaría & 0 \\
\hline
\end{tabular}

Nota: Fuente: Standard postage Stamp Catalogue Scoot, 2010.

En 1985 se emiten 2 estampillas dedicadas al Monumento al Agricultor, cada una con diseños totalmente diferentes, ya que la primera enfocaba solamente la escultura y la segunda todo el monumento, las dos vistas desde el frente de las obras. 
En 1989 se confeccionó una estampilla en homenaje a la Revolución Francesa en la cual se muestran, junto con el mapa coloreado y la bandera de Francia, la escultura principal del Monumento Nacional, vista desde un contrapicado desde el noroeste de la estatua.

En el 2006, se editaron 2 estampillas con diseños muy distintos entre sí, que ilustran monumentos escultóricos completos distintos. Las dos de las estampillas son parte de una hoja filatélica conmemorativa al 150 aniversario de la Campaña Nacional. Representan el Monumento Nacional (desde el suroeste) y el Monumento a Juan Santamaría (desde el noroeste), junto a las imágenes de Juan Rafael Mora Porras y el Mesón de Guerra, respectivamente. Toda la producción filatélica por años se resume en la Figura 2.

Además de las estampillas ya mencionadas, existen los casos de las sobreimpresiones. Se trata de estampillas que eran reutilizadas al remarcarles algunos elementos que las validaran para la circulación. En algunos casos las sobreimpresiones buscaban validar una función específica del timbre (fiscal, internacional o aéreo), años de validez o revaloración el precio original mostrado en el impreso. Existen 4 diseños que muestran esculturas monumentales que fueron sobreimpresos: una con tres sobreimpresiones y el resto solo un remarcaje, cada una. En los casos estudiados, dos de las sobreimpresiones revaloraban la estampilla y otras cinco le especificaban el uso o años. De todas las estampillas sobreimpresas, el monumento a Juan Santamaría se representaba en tres ocasiones, mientras que en la restante se consignaba la estatua a Juan Rafael Mora Porras (Figura 3). Todas estas reimpresiones se realizaron entre 1907 y 1941.

Existen dos casos especiales en cuanto a la utilización de las sobreimpresiones. En los años de 1955 y 1974 se emitieron estampillas con la imagen del Monumento Nacional sobreimpresa, que a diferencia de las otras ya estudiadas, nunca salieron al mercado sin la sobreimpresión. Por tal razón, en este estudio se analizaron como un diseño completo y no como un sobreimpreso (Ver Tabla 1).

$\mathrm{Al}$ relacionar los valores de las estampillas con las tarifas establecidas en los momentos de circulación, las que tenían como motivo alguno de los monumentos mencionados consignaban los valores más bajos, por lo tanto, eran de uso más frecuente en el gravamen del correo; lo que significa que circulaban en gran cantidad, lo que implica que podían ser potencialmente vistas por una gran parte de la población. Las estampillas con precios de 85 colones fueron puestas en circulación en el 2006, pero el resto marca precios menores a 30 colones. El precio específico de estas estampillas en el momento de su puesta en circulación se muestra en la Figura 4.

Al considerar todo lo anterior, se puede decir que el Estado costarricense exaltó los valores patrióticos (honor y sacrificio) al enfatizar la reproducción de obras escultóricas relacionadas con la Campaña Nacional, promovió además los 


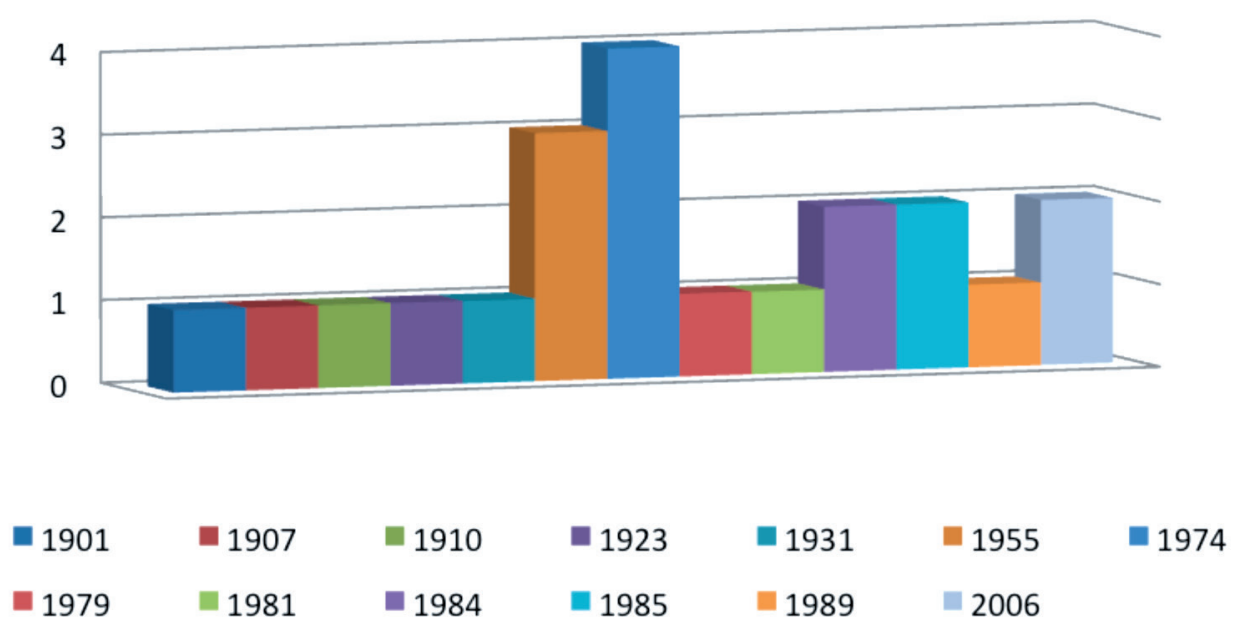

Figura 2. Año de emisión de estampillas costarricense que representaban esculturas públicas. Fuente: Standard postage Stamp Catalogue Scoot 2010. Elaboración propia.

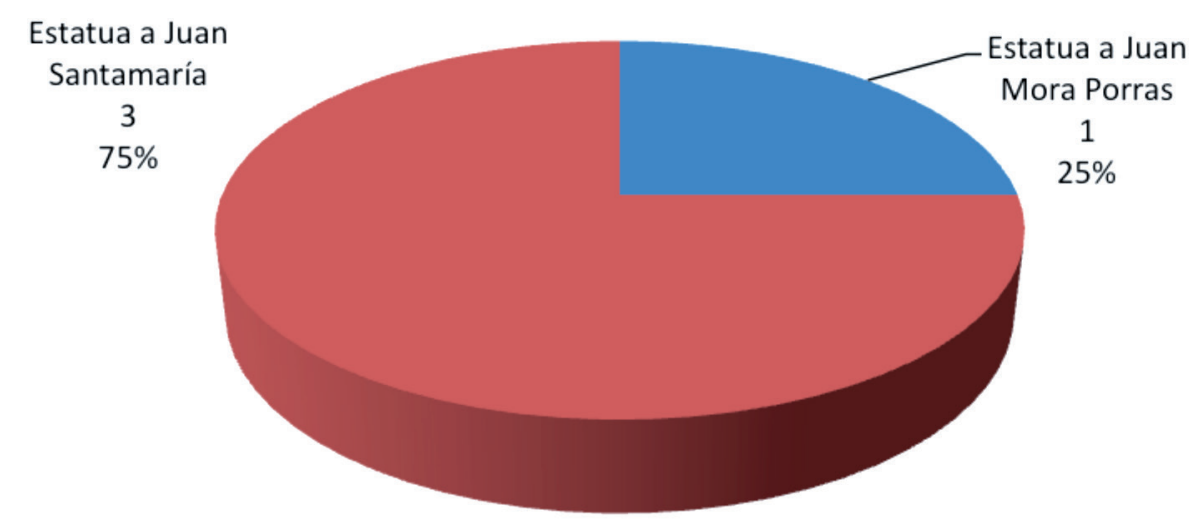

Figura 3. Estampillas con diseños de esculturas públicas costarricenses que fueron sobreimpresas. Fuente: Standard postage Stamp Catalogue Scoot 2010. Elaboración propia.

valores del trabajo, el esfuerzo y la paz, al reproducir el Monumento al Trabajador. Lo anterior, confirma diversas investigaciones que demuestran el papel cumplido por algunas esculturas nacionales en la exaltación de ciertos hechos históricos, en concreto de la Campaña Nacional, como los trabajos elaborados por Oscar Aguilar Bulgarelli (1991), Patricia Fumero Vargas (1998), Annie Lemistre Pujol (1988), Iván Molina Jiménez y Steven Palmer (1992) y David Díaz Arias (2010). Por tanto, se puede afirmar que la filatelia costarricense enalteció y promovió el bronce de la patria, como imagen de la identidad nacional costarricense. 


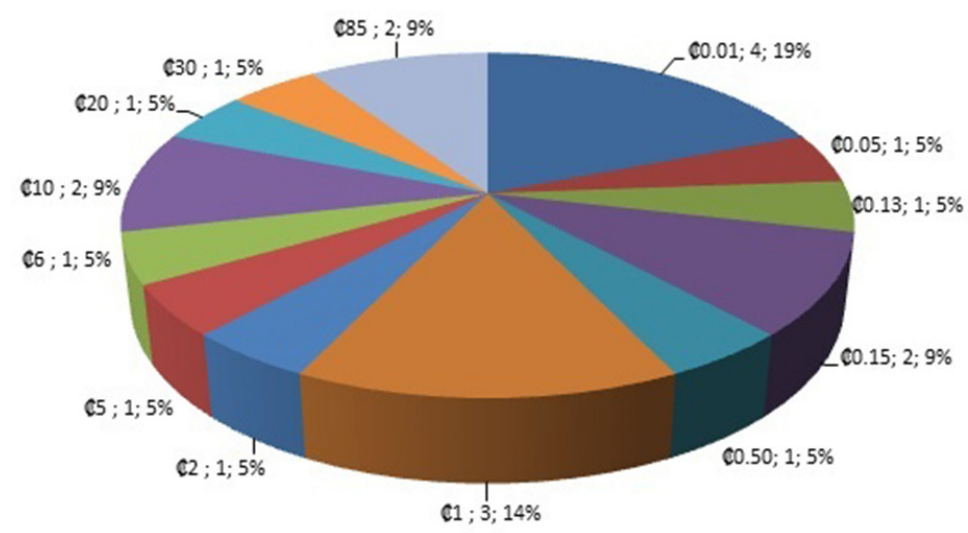

Figura 4. Valores faccionales y cantidad estampillas costarricenses que representan esculturas públicas. Fuente: Standard postage Stamp Catalogue Scoot 2010. Elaboración propia.

\section{"DE MANO EN MANO". LA REPRESENTACIÓN DE LA ESCULTURA PÚBLICA MONUMENTAL EN LA NUMISMÁTICA}

Más que un mero medio de intercambio económico, cronológicamente, las monedas primero y los billetes después son un medio de trasmisión de ideas de los estados o entes emisores de los mismos. Esto debido, en gran parte, a que desde la antigüedad los gobernantes deseaban evidenciar su control hasta el último rincón de sus dominios, y de esta manera llegaban a los lugares donde una moneda o un billete sirven como medio de intercambio de mercancías (Hidalgo, 2009, p. 7). De esta manera, se han desarrollado estudios que permiten conocer, por ejemplo, la prosperidad económica, el impulso artístico, el desarrollo de ideas teológicas y el perfeccionamiento metalúrgico del imperio bizantino, con solo estudiar de forma "superficial" las monedas de dicha cultura (Foos y Maggadino, 1996, pp. 91-96). En el caso de que una moneda o billete muestre un monumento escultórico, en esta imagen se hace evidente un sesgo, una modificación y una reinterpretación del mensaje original de la obra, ya que esta puede ser distorsionada al eliminar o agregar elementos adicionales.

Un aspecto interesante al estudiar la numismática de Costa Rica, como medio de remisión de conceptos o mensajes, es el hecho de que por algunos años (1885-1897),la emisión de monedas y billetes corrió por cuenta de bancos privados (Carranza, 2012, p. 159), (Murillo, 2005 p. 87). De esta forma, el mensaje transmitido en diversos medios de intercambio no representaba, necesariamente, 
una visión estatal, sino la posición de las clases dominantes o una mercadotecnia sobre lo que deseaban comunicar en ellos.

En la numismática nacional no se ha producido ninguna moneda con la imagen de alguna escultura patria impresa. Esto sucede en parte por la dificultad en la producción de metálico (llegando hasta al resello), por lo que las complejidades de los diseños fueron mínimas. Con la asignación del Banco Central para la producción de la moneda se da un aumento de la calidad de la producción y número de emisiones, pero eso no significó la emisión de monedas de circulación con iconografías de monumentos escultóricos.

Por el contrario, se elaboraron cuatro monedas conmemorativas que aludían a monumentos cívicos: tres se dedicaron al Monumento a Juan Santamaría y la cuarta, al Monumento a la Madre. En cuanto a la imagen representada, las monedas de 1970 mostraban la figura de Juan Santamaría sin incluir el pedestal y con un cañón de época al frente de la estatua. En el caso de la escultura a la maternidad de Francisco Zúñiga, se representa sin pedestal. Las monedas diseñadas en 1981, utilizan la misma imagen de Juan Santamaría: se consigna la escultura sola, sin base o pedestal.

Por su valor nominal se dio una clara segregación entre los monumento representados. Mientras el Monumento a la Madre se cotizaba en 25 colones, los billetes con iconografía de Juan Santamaría tenían valores entre los 200 y 300 colones, hasta la exorbitante suma de 5000 colones. De hecho este valor solo será igualado o superado por 6 monedas conmemorativas, y es importante considerar que en su momento de acuñación estos precios eran realmente poco vistos y usados en la cotidianidad, superando por mucho las denominaciones que circulaban en esa época (la moneda de mayor denominación en circulación era de 2 colones y el billete de 1000 colones). Igualmente, el material utilizado para representar a Juan Santamaría fue dos veces oro, y en una ocasión, plata; mientras que en el caso del monumento a la maternidad se usó solamente la plata (Tabla 2).

Debido a que la numismática también estudia medallas conmemorativas, es digno mencionar la medalla confeccionada con motivo de la inauguración del Monumento Nacional en 1895, que se entregó a los excombatientes de la guerra de 18561857. En el anverso dice: "Monumento Nacional/ 15 de setiembre / 1895", mientras que al reverso se lee: "A / los soldados / de la campaña / de 1856 y 1857/ la patria Reconocida". Esta medalla tiene un valor excepcional, ya que no solo reproduce la escultura de forma frontal para su fecha de inauguración, sino que es, en sí misma, una aceptación conceptual al mensaje del monumento (Murillo, 2005, p. 132).

Por otro lado, desde 1858 se emitieron billetes para Costa Rica, aunque desde la década de 1870 se han impreso prácticamente en el extranjero, debido a la búsqueda de técnicas de seguridad contra falsificaciones. Esto implica altos costos de elaboración, y por tanto cuidadoso proceso en todo lo relacionado con el diseño 


\section{Tabla 2}

MONEDAS CONMEMORATIVAS QUE REPRESENTAN MONUMENTOS

ESCULTÓRICOS PÚBLICOS

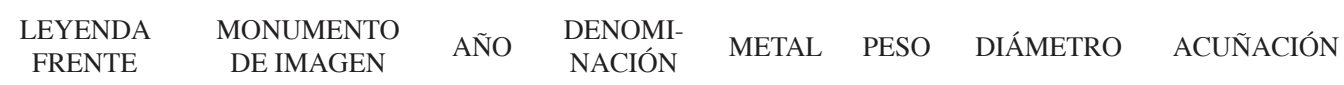

Juan Santamaría héroe nacional $1856 / 200$ colones

25 de legislación social $/ 25$ colones

\section{Monumento a la}

Madre

1970

25

999 plata

$53,9 \mathrm{~g}$

$60 \mathrm{~mm}$

6800 piezas

proof
125 aniversario/ 1856-1981/Juan Santamaría
Juan Santamaría

1981
925

plata,

0,75

cobre

$11 \mathrm{~g} \quad 27 \mathrm{~mm}$

10000 piezas prof con pulido en mate

de los billetes, los cuales no eran, en absoluto, aleatorios. El esbozo de las imágenes era sumamente meticuloso y se les encargaba a artistas y creadores profesionales. Debido a que por varios años, como ya se mencionó, no existió un único emisor de papel moneda, y cuando el Estado tuvo un ente emisor, este no fue el mismo, se generó una amplitud en la variedad de la iconografía y los temas que ilustraban los billetes nacionales. De todos los billetes que han circulado en el país, solamente 9 
han mostrado, ya sea en su anverso o reverso, un monumento escultórico de este país. Como se muestra en la Figura 5, tres se dedicaron al Monumento Nacional, cuatro al Monumento a Juan Santamaría y solamente uno al Monumento a Juan Mora Porras.

Entre 1908 y 1912 el Banco de Costa Rica emitió un billete cuyo anverso mostraba el monumento a Juan Santamaría, en dicho billete la escultura se muestra desde una vista de tres cuartos de frente, sin que se visualice la base del monumento. Pocos años después, se representa el Monumento Nacional gracias al Banco Anglo Costarricense, entre 1909 y 1917, mediante un grabado de todo el conjunto monumental desde su costado norte, junto en su base, que sirven para mostrar la escala de la obra. Entre 1931 y 1936 el Banco Internacional de Costa Rica emite un billete en el cual se representa el pedestal y la escultura del monumento a Juan Mora Porras, visto desde su costado sur. El mismo banco emite, entre 1933 y 1934 un billete que representa al Monumento Nacional, desde su costado sureste. Al crearse el Banco Nacional de Costa Rica con la base del Banco Internacional, se retoma el diseño de 1933-1934, con el nombre del nuevo banco, entre 1941 y 1942. Con la instauración del Banco Central de Costa Rica como único ente emisor del país, este elaborará tres billetes con un diseño muy similar, entre 1952 y 1969 , en los cuales se representaba todo el Monumento a Juan Santamaría, desde el suroeste del mismo. Véase la Tabla 3.

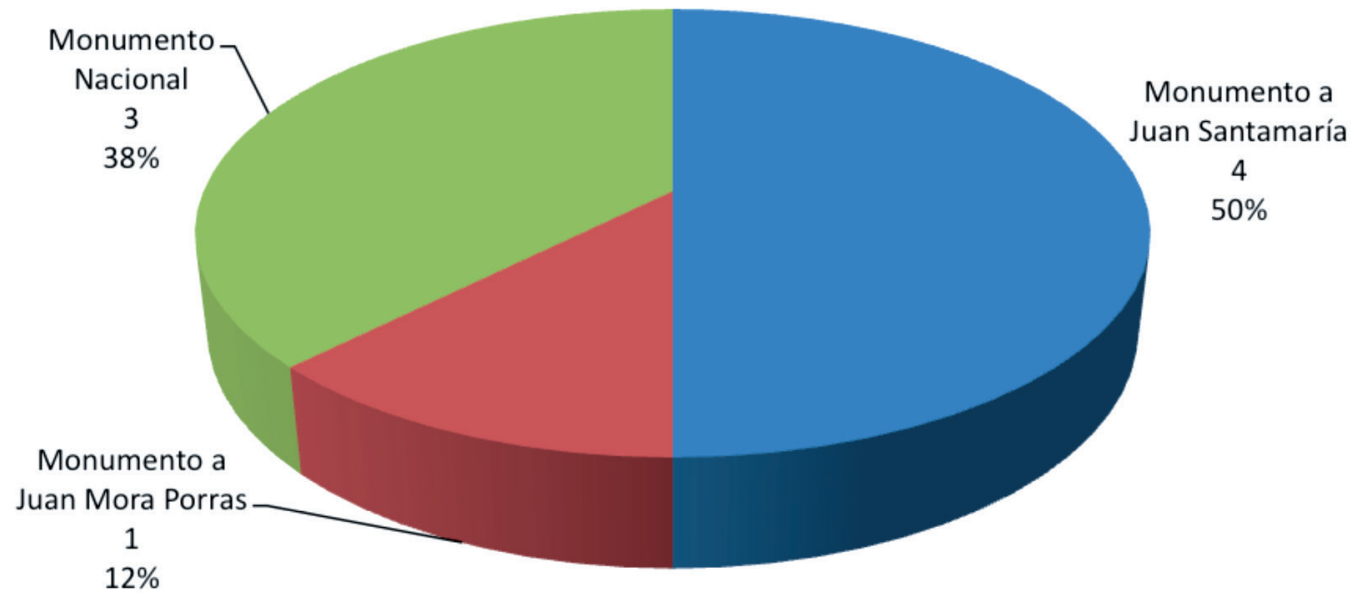

Figura 5. Esculturas públicas representadas en los billetes costarricenses.

Fuente: Murillo, 2005. Elaboración propia.

En cuanto a las imágenes que acompañaban a las de los monumentos escultóricos patrios pueden denotarse algunos patrones. Los billetes emitidos por el Banco Central entre 1952 y 1969, se relacionaron con el Monumento a Juan Santamaría 
Tabla 3

BILLETES DE CIRCULACIÓN NACIONAL QUE REPRESENTAN MONUMENTOS

ESCULTÓRICOS PÚBLICOS

\begin{tabular}{|c|c|c|c|c|c|c|}
\hline Anverso & Reverso & Emisor & Año & Valor & Dimensiones & Emisión \\
\hline $\begin{array}{l}\text { Monumento a Juan } \\
\text { Santamaría }\end{array}$ & $\begin{array}{l}\text { Edificio del Banco } \\
\text { de Costa Rica }\end{array}$ & Banco de Costa Rica & 1908-1912 & $\notin 20$ & $18,7 \times 8,0 \mathrm{~cm}$ & 59999 \\
\hline $\begin{array}{l}\text { Retrato de Percy G } \\
\text { Harrison }\end{array}$ & $\begin{array}{l}\text { Monumento } \\
\text { Nacional }\end{array}$ & $\begin{array}{l}\text { Banco Anglo } \\
\text { Costarricense }\end{array}$ & 1909-1917 & $\not 20$ & $18,9 \times 8,7$ & 13000 \\
\hline $\begin{array}{l}\text { Monumento a Juan } \\
\text { Mora Porras }\end{array}$ & $\begin{array}{l}\text { Fotografía } \\
\text { Cogedoras de café }\end{array}$ & $\begin{array}{l}\text { Banco Internacional } \\
\text { de Costa Rica }\end{array}$ & $1931-1936$ & $\notin 5$ & $18,5 \times 8,5$ & 600000 \\
\hline Cogedora de Café & $\begin{array}{l}\text { Monumento } \\
\text { Nacional }\end{array}$ & $\begin{array}{l}\text { Banco Internacional } \\
\text { de Costa Rica }\end{array}$ & 1933-1934 & $\not 50$ & $18,5 \times 8,4 \mathrm{~cm}$ & 80500 \\
\hline Cogedora de Café & $\begin{array}{l}\text { Monumento } \\
\text { Nacional }\end{array}$ & $\begin{array}{l}\text { Banco Nacional de } \\
\text { Costa Rica }\end{array}$ & $1941-1942$ & $\not 550$ & $18,5 \times 8,4$ & 69500 \\
\hline $\begin{array}{l}\text { Retrato de Juan } \\
\text { Rafael Mora Porras }\end{array}$ & $\begin{array}{l}\text { Monumento a Juan } \\
\text { Santamaría }\end{array}$ & $\begin{array}{l}\text { Banco Central de } \\
\text { Costa Rica }\end{array}$ & $1952-1960$ & $\not 100$ & $15,6 \times 6,7$ & 1000000 \\
\hline $\begin{array}{l}\text { Retrato de Juan } \\
\text { Rafael Mora Porras }\end{array}$ & $\begin{array}{l}\text { Monumento a Juan } \\
\text { Santamaría }\end{array}$ & $\begin{array}{l}\text { Banco Central de } \\
\text { Costa Rica }\end{array}$ & 1961-1966 & $\not 100$ & $15,6 \times 6,7$ & 1500000 \\
\hline $\begin{array}{l}\text { Retrato de Juan } \\
\text { Rafael Mora Porras }\end{array}$ & $\begin{array}{l}\text { Monumento a Juan } \\
\text { Santamaría }\end{array}$ & $\begin{array}{l}\text { Banco Central de } \\
\text { Costa Rica }\end{array}$ & 1966-1969 & $\notin 100$ & $15,6 \times 6,7$ & 1500000 \\
\hline
\end{tabular}

Nota: Fuente: Carranza Astúa 2012.

60 Diálogos: Revista Electrónica de Historia, ISSN: 1409-469X, Vol. 15 № 2, setiembre 2014 - enero 2015 / pp. 49-67, San José, Costa Rica 
y con el retrato del presidente Juan Rafael Mora Porras. Por otra parte, los billetes emitidos entre 1931 y 1942, por el Banco Internacional y el Banco Nacional concernieron al Monumento Nacional y al Monumento de Juan Mora Porras con la imagen de las "Cogedoras de Café". Dado lo anterior, estos billetes mostraban imágenes "típicas" o "tradicionales" del país. Los otros dos diseños elaborados en la primera década del siglo XX presentan el Monumento mezclado con representaciones pictóricas del banco emisor, como institución. Ver Figura 6.

En el caso de los billetes impresos con diseños que incluían monumentos escultóricos, la denominación que representaban tenía valores medios altos, generalmente el penúltimo de los valores representados en los billetes en circulación. Por esta razón dichos diseños no solamente fueron de alta circulación, sino que, socialmente, se vincularon con una elevada cotización y un valor superior. Los valores nominales de $\varnothing 100$ se muestran en tres emisiones, mientras que los de $\varnothing 50$ y $\varnothing 20$ se presenta en 2 cada uno y solo un billete se valoró en $\varnothing 5$, como se muestra en la Figura 7.

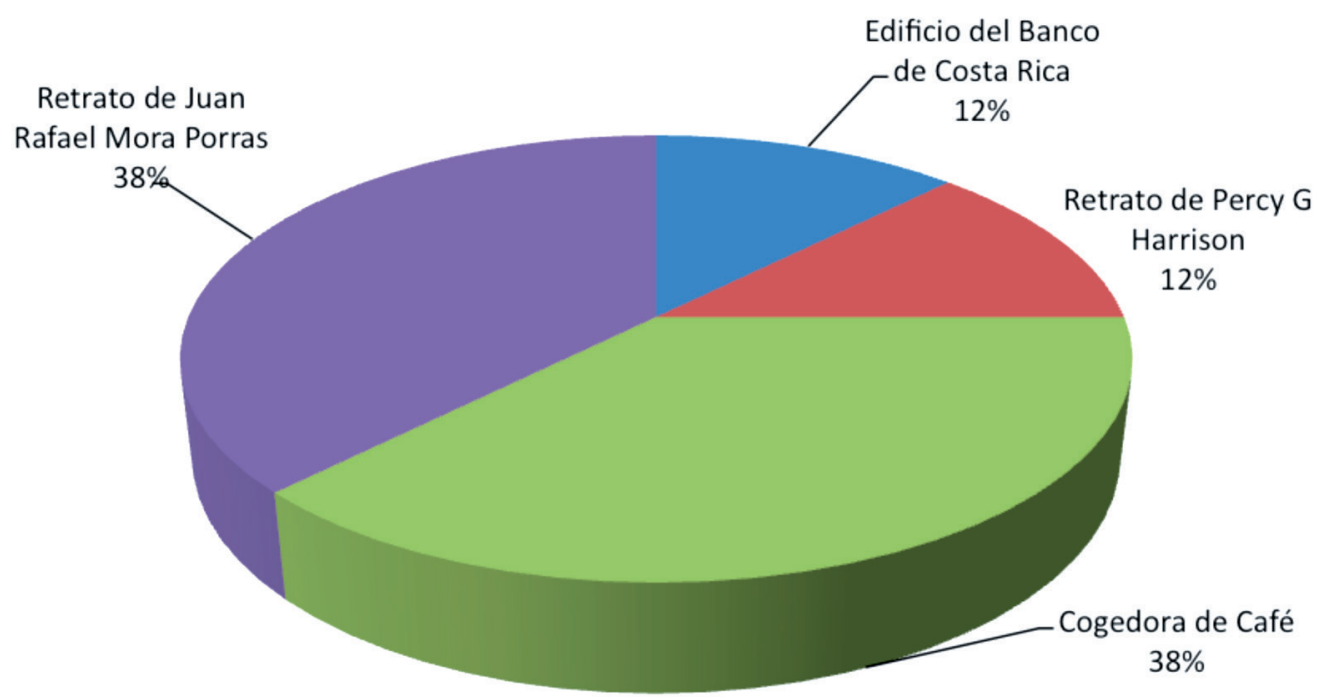

Figura 6. Imágenes acompañantes a los monumentos escultóricos costarricenses.

Fuente: Carranza Astúa, 2012. Elaboración propia.

Por otro lado, del total de las emisiones realizadas con diseños donde se muestran monumentos escultóricos costarricenses, según el volumen de emisión, los diseños donde se expone el Monumento a Juan Santamaría son los más representados, con una producción de billetes de un poco más de cuatro millones. El Monumento Nacional aparece en un poco más de un millón seiscientos mil billetes y el Monumento a Juan Rafael Mora solo en unos seiscientos mil. Estas cifras deben 
considerarse en el marco de la cantidad de emisiones diferentes que se elaboraron con cada boceto. De esta forma, del Monumento a Juan Santamaría se editaron cuatro diseños y del Monumento Nacional, tres; mientras que con la imagen del Monumento a Juan Mora solo uno; esto explica los datos que se evidencian en la Figura 8.

Debido a las circunstancias históricas, las entidades que emitieron billetes bajo su nombre en Costa Rica fueron muchas: El Banco Nacional de Costa Rica (1858-1859), el Banco Anglo Costarricense (1864-1912), el Banco Nacional (1867-1877), el Banco de Emisión (1876-1881), el Banco Herediano (1879-1881), el Banco Nacional (1877-1889), el Banco de Costa Rica (1891-1914), el Banco Comercial (1907-1915), el Banco Mercantil de Costa Rica (1910- 1925), el Banco Internacional de Costa Rica (1914-1936), la República de Costa Rica (1865-1921), las Municipalidades nacionales (1917-1918), el Banco Nacional (1937-1949) y el Banco Central (desde 1950). De todas estas entidades solamente el Banco de Costa Rica, el Banco Anglo Costarricense, el Banco Internacional de Costa Rica, el Banco Nacional de Costa Rica y el Banco Central han emitido billetes donde monumentos escultóricos nacionales sean parte del diseño del papel moneda, como se nota en la Figura 9.

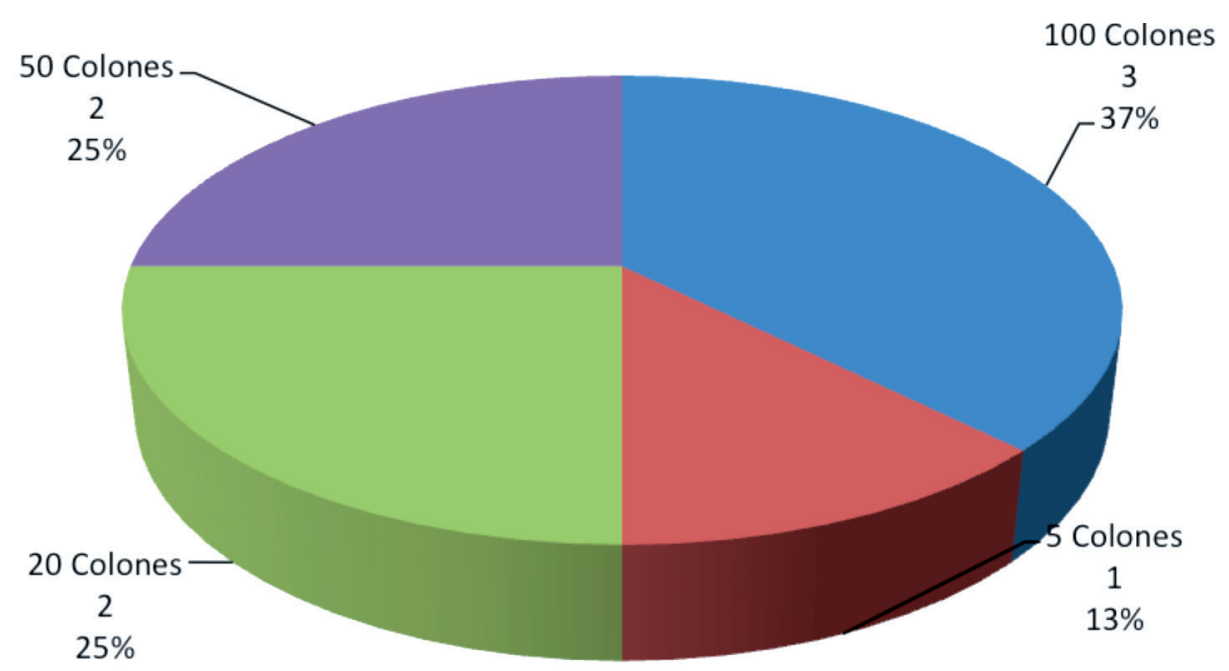

Figura 7. Valor nominal de los billetes que representan a monumentos escultóricos costarricenses. Fuente: Carranza Astúa, 2012. Elaboración propia. 


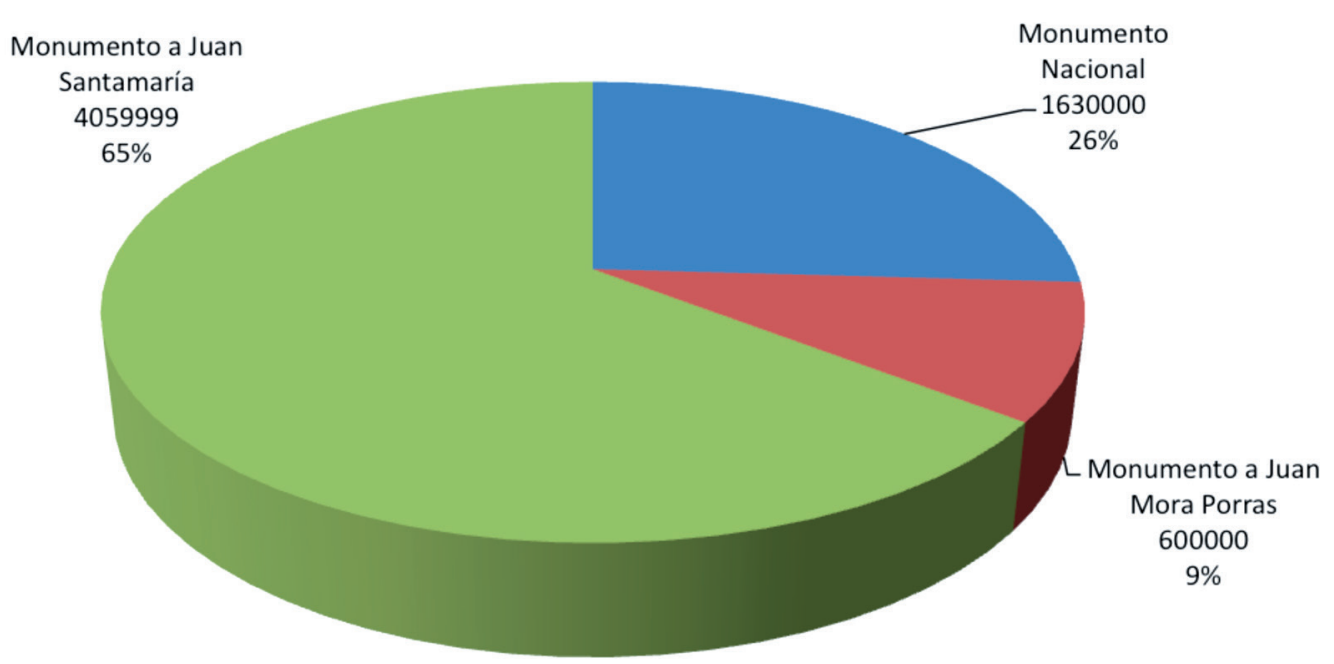

Figura 8. Emisión de total de billetes según el monumento escultórico representado. Fuente: Carranza Astúa, 2012. Elaboración propia.

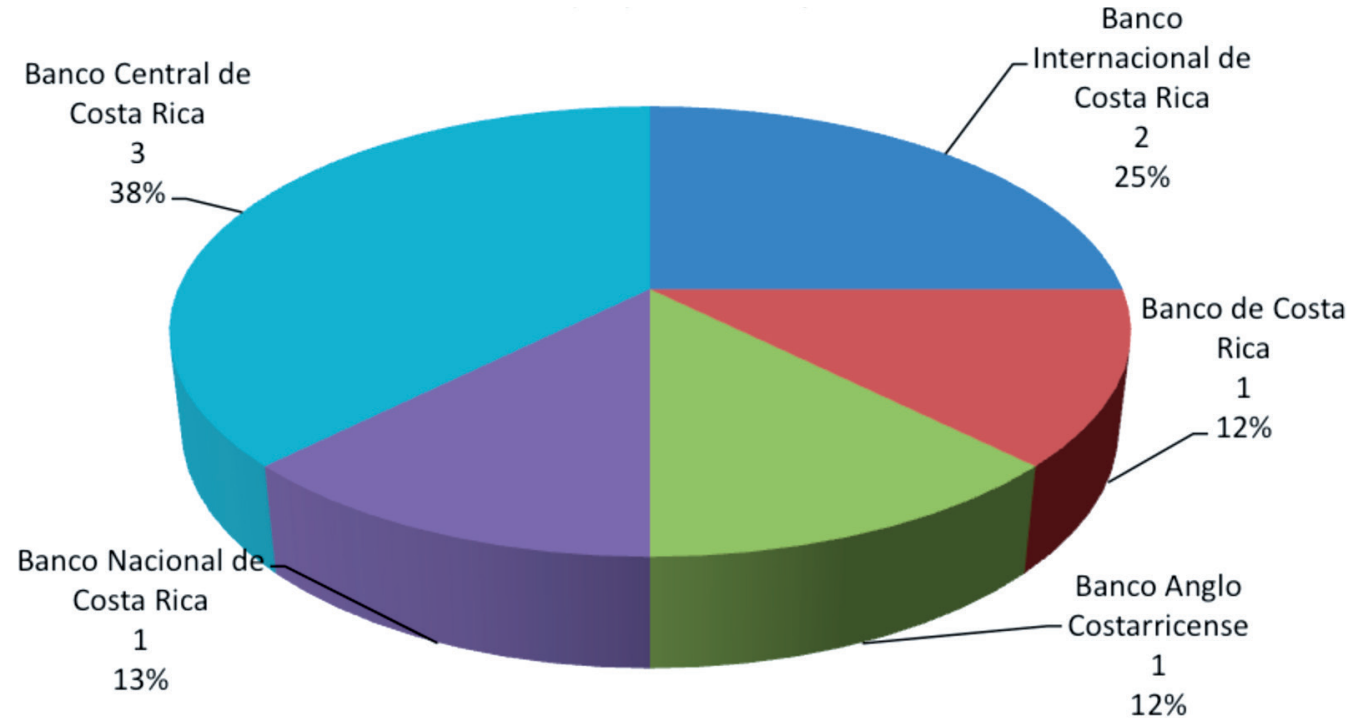

Figura 9. Entes emisores de billetes con imágenes de esculturas monumentales. Fuente: Carranza Astúa, 2012. Elaboración propia.

La interpretación sobre el mensaje de los diseños trasmitidos en las monedas y billetes se asemeja al de la filatería, donde queda clara la intención del Estado de rescatar la Campaña Nacional como una constante. Sin embargo, en este caso 
particular, es evidente un cambio marcado con respecto a la utilización de la imagen de Juan Mora, en comparación con la Campaña Nacional y posteriormente, con la iconografía correspondiente al Monumento a Juan Santamaría. Esto se debe, sobretodo, a la fuerza que tomó, cada vez más, la celebración de la festividad del 11 de abril o del "Día de Juan Santamaría" en el calendario patrio, así como su referencialidad en el discurso nacionalista costarricense.

\section{DOS IDEALES Y TRES ESCULTURAS. CONSIDERACIONES FINALES}

Es evidente que tanto las monedas, los billetes y los sellos postales son más que simples objetos fiduciarios, son textos de difusión ideológica, que tienen esta función claramente definida. Si bien, por sí mismas son obras artísticas en pequeño formato, su intencionalidad comunicativa expresa una esmerada realización en las artes gráficas, la cual declara la necesidad de que el mensaje predeterminado sea perfectamente legible. (Hidalgo, 2009, p. 51)

Tanto en la numismática como en la filatería nacional se siguieron patrones similares para su producción general. En primer lugar, la escultura de Juan Santamaría es el monumento más reproducido, seguido por la figura de Juan Mora Porras, sobre todo en la primera mitad del siglo XX. Se reprodujo en menor medida el Monumento al Agricultor, representante claro de la escultórica cívica de la segunda mitad del siglo XX.

Pareciera que en cuanto más se fortalecían las festividades cívicas del 11 de abril y se conformaba la figura de Juan Santamaría como héroe nacional, cada vez fue más común su reproducción. Esta imagen se reprodujo con gran dedicación y esmero técnico, y además con mayor variedad en los diseños. Por otro lado, a inicios del siglo XX, cuando la conmemoración de la Campaña Nacional se enfocaba en la figura de Juan Mora Porras, la figura es este prócer es representada con más frecuencia, siendo posteriormente prácticamente nula. En la mayoría de las imágenes sobre la Campaña Nacional se reprodujo el monumento con el pedestal o parte de él, lo que trasmite una sensación de monumentalidad e importancia del evento, monumentalidad de la obra escultórica que es análoga a la monumentalidad historia del acontecimiento.

Por su parte, cuando la fama de Francisco Zúñiga se elevó en el país al recibir el Premio Nacional de Cultura Magón en 1973 y el de Escultura en 1979 (Ferrero, 1990 , p. 21) y las condecoraciones en el extranjero lo visibilizaron como artista nacional, se cambió la perspectiva sobre el arte monumental nacional y los creadores locales ${ }^{1}$. De esta forma, se le adjudicará a Zúñiga, no solo la construcción del Monumento al Trabajo y la exhibición con grandes honores del Monumento a la 
Madre $^{2}$, sino que también se le encargó la reproducción de sus obran en estampillas o monedas nacionales. En estos diseños normalmente se reprodujeron las obras sin pedestal, y se enfocó en la transmisión de la escultura principal, con lo cual se produjo una reducción el mensaje visual a su mínima expresión, lo cual estaba orientado a un deseo de magnificar el sentimiento expresado en cada una de ellas: el amor maternal y la laboriosidad agrícola.

De esta manera, es claro que básicamente se promovieron dos ideales en la filatería y la numismática. Por un lado se tomó la Campaña Nacional como el hito creador de la patria costarricense, reproduciendo su significado en la patria grande, el gobernante necesario y el esfuerzo del pueblo llano. Por otro lado, en la producción de las obras de Francisco Zúñiga, donde se alaba la actividad económica, los valores sociales y el desarrollo social promovidos por el Estado Gestor, en manos del creador plástico más famoso hasta ese momento en la escultórica costarricense. En otras palabras, la representación de monumentos patrios en la numismática y filatería nacional remarca el hito creador de la identidad nacional costarricense y el fruto de sus políticas sociales en las manos de su artista más afamado.

\section{REFERENCIAS}

Aguilar, O. (1991). El pedestal de Santamaría. Serie Cuadernos de Cultura Museo Histórico Juan Santamaría, (11). 40.

Carranza, J. (2012). Historia de los billetes de Costa Rica, 1858-2012. Costa Rica: J. Carranza A.

Díaz, D. (2004). Fiesta e imaginería cívica: La memoria de la estatuaria de las celebraciones patrias costarricenses, 1876-1921. Revista de Historia Escuela de Historia Universidad Nacional/ Centro de Investigaciones Históricas, (49-50), 111-154.

Díaz, D. (2002). Invención de una tradición: La fiesta de la independencia durante la construcción del estado costarricense, 1821-1874. Revista de Historia Escuela de Historia Universidad Nacional/Centro de Investigaciones Históricas (45), 105-162.

Díaz, D. (2003). Reforma sin alianza, discursos transformados, interés electoral, triunfos dudosos. La nueva interpretación histórica de la década de 1940 (Serie de Historia de las Instituciones de Costa Rica N7). Costa Rica: EUCR.

Dirección de Correo y Telégrafos. (2011). La Filatelia en Guatemala 1871-2011. Guatemala: Dirección General de Correos y Telégrafos. 
Ferrero, L. (1985a) Zúñiga Costa Rica Colección Daniel Yankelewitz. Costa Rica: Editorial Costa Rica.

Ferrero, L. (1985b). Zúñiga: Costa Rica. Costa Rica: Museo de Arte Costarricense.

Ferrero, L. (1986). Sociedad y arte en la Costa Rica del siglo XIX. Costa Rica: EUNED.

Ferrero, L. (1991). Escultores costarricenses (1973-1990). Costa Rica: Editorial de Costa Rica.

Ferrero, L. (1991). La Escultura en Costa Rica (4 reimp). Costa Rica: Editorial Costa Rica.

Ferrero, L. (1998) Juan Ramón Bonilla. Un escultor costarricense de principios del siglo XX. Costa Rica: Editorial Mesén.

Ferrero, L. (2001). Guía interpretada del Salón Dorado. Costa Rica: Museo de Arte Costarricense.

Foss, C. y Magdalino, P. Roma y Bizancio II. España: Folio, SA.

Fumero, P. (1998). El Monumento Nacional, Fiesta y develación, septiembre de 1895. Costa Rica: Museo Histórico Cultural Juan Santamaría.

Hidalgo, E. (2009). Antecedentes del Diseño Filatélico en Costa Rica. (Tesis de grado) Universidad de Costa Rica. Costa Rica.

Lemistre, A. (1988). Bronces conmemorativos y una gesta heroica: la Estatua de Juan Santamaría y el Monumento Nacional. Costa Rica: Museo Histórico Cultural Juan Santamaría.

Molina, I. y Palmer, S. (Eds.). (1992). Héroes al gusto y libros de moda: sociedad y cambio cultural en Costa Rica, 1750-1900. Costa Rica: Porvenir-Plumsock Mesoamericana Studies.

Murillo, J. (2005). Historia de las monedas de Costa Rica. Costa Rica. EUNED.

\section{Citas y Notas}

1 Después de 1975, el Estado costarricense asignara exclusivamente a nacionales para la realización de monumentos escultóricos.

2 Aunque creada en 1935, no fue exhibida en el lugar asignado en el Hospital Carit, hasta 1955 y tratado como una “obra de Zúñiga” hasta la década 1970 (Ferrero, 1985. .p. 87). 


\section{ACERCA DEL AUTOR}

Leoncio Jiménez Morales: Costarricense. Máster en Historia Aplicada de la Universidad Nacional de Costa Rica. Enfocado en el estudio de la escultórica costarricense. Docente del MEP y de la UACA. leonciojm@gmail.com 
